\title{
PRAKTEK KHITAN PADA PEREMPUAN DALAM PERSPEKTIF HUKUM ISLAM DI DESA RAWAKALONG KECAMATAN GUNUNG SINDUR KABUPATEN BOGOR
}

\author{
Nurahmansyah \\ Prodi Ahwal Syakhshiyyah, Fakultas Agama Islam, Universitas Nahdlatul Ulama \\ Indonesia \\ E-mail: nurahmansyah@gmail.com
}

\begin{abstract}
Article Information
Informasi Artikel

Naskah diterima: 30

Maret 2019

Naskah direvisi: 7 April 2019

Naskah disetujui: 10

April 2019

Naskah dipublish: 12

April 2019

Kata Kunci Khitan

Perempuan,

Rawakalong, Hukum

Islam

Abstrak
Khitan perempuan yang dilaksanakan di Desa

Rawakalong hanya sebagai simbol. Pelaksanaan khitan pada bayi perempuan di desa tersebut memiliki dua tahapan, yaitu: tahap persiapan y aitu bayi perempuan yang akan dikhitan diberi sarapan/tatakan dengan kain puth yang sudah disiapkan terlebih dahulu. Adapun tahap pelaksanaan dengan meletakan koin di bawah klitoris bersamaan dengan pembacaan doa atau jampe-jampe dengan Bahasa Sunda yang dibaca oleh paraji, lalu menorehnya dengan pisau kecil atau pisau lepit. Khitan perempuan tersebut merupakan sebuah tradisi yang sudah dilaksanakan sejak zaman dahulu (nenek-moyang mereka)
\end{abstract}

\section{PENDAHULUAN}

Islam adalah agama yang sangat menjunjung tinggi nilai-nilai kemanusiaan, termasuk didalamnya nilai kesetaraan semua manusia dan kesederajatan laki-laki dan perempuan. Khitan atau sunatan sudah sangat familiar dan biasa kita dengar. Dibeberapa tempatacara khitanan anak - anak bahkan dijadikan acarahajatan, undangan dan hiburan yang meriah. Khitan sudah dilakukan sejak zaman pra sejarah. Hal tersebut bisa diamati dari lukisan-lukisan yang terdapat dalam gua-gua pra sejarah. Praktek khitan telah lama dikenal sejak zaman Mesir Kuno. Hal itu dibuktikan dengan ditemukannya fenomena khitan pada mummi perempuan yang hidup pada abad ke-16 sebelum Masehi (16S M), jauh sebelum Islam datang1. Demikian pula diberbagai negara dan suku, termasuk Indonesia, tradisi khitan atau sunat bisa dilihatkan di

\footnotetext{
${ }^{1}$ Setiawan Budi Utomo, Fiqih Aktual:Jawaban Tuntas Masalah Kontemporer, (Jakarta: Gema Insani Press, 2003), h. 303
} 
Museum Batavia, Jakarta yang memperlihatkan zakar asli pria suku badui yang telah dikhitan $^{2}$

Kata "khitan" berasal dari kata khatn, yang berarti bagian yang dipotong dari kemaluan laki-laki dan perempuan. Tetapi ada yang mengatakan, bahwa al-khatn digunakan untuk anak laki-laki. Sedangkan untuk anak perempuan digunakan kata $a l$ $k h i f a d^{3}$.Untuk memotong keduanya disebut al- I'dzar dan al-khifad. Sedangkan pengertian khitan menurut istilah adalah memotong sebagian anggota tertentu ${ }^{4}$. Khitan anak laki-laki adalah memotong, atau menghilangkan kulit yang menutupi hasyafah (pucuk dzakar), agar terbukalah hasy afah tersebut. Adapun khitan bagi perempuan, atau biasa disebut khifad, yakni memotong sebagian kecil dari kulit kemaluan yang menonjol di atas lubang kencing (klitoris). Namun, dalam hal ini Rasulullah SAW mengingatkan bahwa dalam memotong tidak boleh berlebihan ${ }^{5}$.

Dalam syariat Islam, khitan merupakan suatu ajaran yang dibawa oleh Nabi Muhammad saw. Sebagai kelanjutan dari ajaran Nabi Ibrahim A.S. Disebutkan dalam sebuah hadits6. "Nabi Ibrahim berkhitan setelah mencapai usia 80 tahun (melalui perintah Allah) dan Nabi Ibrahim di Qadum." (HR Bukhari Muslim) ${ }^{7}$.

Kata al-Qodum adalah alat tukang kayu. Menurut Ibnu Hajar Asqolani mengatakan, yang dimaksud dalam hadis di atas adalah alat yang digunakan untuk berkhitan / kapak $^{8}$. Dalam sebagian riwayat sirah Nabi Muhammad SAW. Diperoleh keterangan bahwa beliau dilahirkan dalam keadaan bersih dan suci dengan kondisi berkhitan serta dipotong pusarnya atas kodrat Allah SWT sebagai keistimewaan kelahiran beliau Rasulullah SAW bersabda9: "Fitrah itu ada lima: khitan, mencukur

\footnotetext{
${ }^{2}$ Hassan Hathout, Revolusi Lentera Perempuan, Obstetri dan dalam Tinjauan Islam (Jakarta: Remaja Rosdakarya,1996), h. 54

${ }^{3}$ Ibnu Qayyim AlJauziah, Tuhfatul MaududbiAh kamil Maulud, (Sudan: Maktabah Qa yyimah,1350), h. 88

${ }^{4}$ Huzaemah Tahido Yanggo, Hukum Keluarga Dalam Islam, (Jakarta:Yayasan Masyarakat Indonesia Baru, 2013), h. 56

${ }^{5}$ Al Ha fidz, Ahsin W, Fikih Kesehatan, (Jakarta, Amzah, 2010)h. 99

${ }^{6}$ Ibnu Qayyim Al Jauziah, Tuhfatul Maududfii ahkamilmaulud, (Sudan: Ma ktabah Qayyimah), h. 89

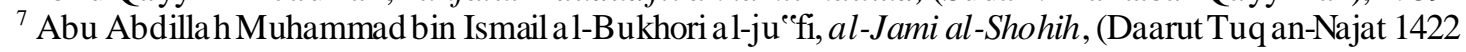

H) Cet ke-1. Jilid 8, h. 66, dan Abu a l-Hasan Muslim bin al-Hajaj al-Qusyairi an-Nisa buri, al-Jami alShohih, (Da rul Ihyait Turos Bairut). Jilid 4, h. 1839

${ }^{8}$ Ahmad ibn „Ali ibn Hajar al-,,Asqalani, Fathal-Bari Bi Syarhi ShohihilBukhori, (Saudi: 2001) Jilid 6, h. 354-355

${ }^{9}$ Huzaemah Tahido Yanggo, Hukum Keluarga dalam Islam, (Jakarta: Yayasan Masyarakat Indomesia Baru, 2013)h.66
} 
bulu di sekitar kemaluan, mencabut bulu ketiak, memotong kuku dan memotong kumis”. (HR. Bukhari dan Muslim, Abu Daud, an-Nasai, Ibnu Hibban) ${ }^{10}$.

Yang dimaksud fitrah disini adalah sunah, artinya khitan itu sunah bukan wajib, oleh karena itu dalam hadis Rasulullah SAW menyebutnya bersamaan dengan hal-hal yang disunatkan. Dan hadis ini bersifat umum, tanpa membedakan antara laki-laki dan perempuan. Khitan selain untuk kesehatan juga berfungsi untuk menjaga kebersihan. Sebab Allah menyukai orang-orang yang menjaga kebersihan.

Imam An-Nawawi dari kalangan ulama mazhab Syafiec $i$ berpendapat bahwa bentuk khitan yang diwajibkan pada laki-laki adalah memotong kulit kulup yang menutupi kepala zakar, sampai terbuka kepala dzakarnya. Sedangkan menurut Abdul Maeealial-Juwaini khitan pada laki-laki wajib memotong kulup, yaitu kulit yang menutupi kepala zakar sedemikian rupa sehingga tidak ada lagi kulup yang tersisa ${ }^{11}$. Adapun mengenai khitan perempuan, ahli fiqih kontemporer,Wahbah Zuhayli dari Suriah dalam al-Fiqhal-Islami wa Adillatuhu menyatakan bahwa khitan bagi perempuan adalah suatu kemuliaan yang jika dilaksanakan dianjurkan untuk tidak berlebihan, agar ia tidak kehilangan kenikmatan seksual12. "Khitan itu di sunnahkan bagi kaum laki-laki dan dimuliakan bagi kaum wanita". (H.R. Ahmad, Baihaqi, dan Baghowi) ${ }^{13}$.

Dalam pemikiran Syekh Yusuf al-Qaradhawi, pendapat yang dianggap baik dan paling dapat diterima oleh logika syara ${ }^{e e}$ dan lebih realitis, hukum bagi perempuan adalah dilakukan khitan ringan saja, sebagaimana terdapat dalam salah satu hadis yang

\footnotetext{
${ }^{10}$ Abu Abdillah Muhammad bin Ismail al-Bukhori al-jue fi, al-Jami al-Shohih, (Da arut Tuq an-Najat 1422 H) Cet ke-1. Jilid 7, h. 160, dan Abu al-Hasan Muslim bin al-Hajaj al-Qusyairi an-Nisaburi, alJami al-Shohih, (Darul Ihyait Turos Bairut). Jilid 1, h. 221, dan Abu Daud Sulaiman bin al-As'ab asSijistani, Sunan Abu Daud, (Maktabah al-,,Asriyah Bairut), jilid 4, h. 84, dan Abu Abdurahman Ahmad bin Syueib al-Khurosani, al-Mujtaba Min al-Sunan, (Maktabah al-Matbu'ah al-Islamiah $1986 \mathrm{~m}$ ), Cet ke-2, jilid 1, h. 13, dan Abu al-Hatim Muhammad bin Hibban al-Darimi, al-Ihsan fi at-Taqribi as-Shohih, (Muassasatu al-Risalah Bairut), jilid 12, h. 292

${ }^{11}$ Setiawan Budi Utomo, Fiqih Aktual:Jawaban Tuntas Masalah Kontemporer, (Jakarta: Gema Insani Press, 2003), h. 300

${ }^{12}$ M.Ali Hasan, Masail Fiqhiyah Al-Haditsah: Pada Masalah-Masalah Kontemporer Hukum Islam, (Jakarta:Raja Grafindo Persada, 2003), h. 203

${ }^{13}$ Abu Abdillah Ahmad bin Muhammad bin Hanbal, Musnad al-Imam Ahmad bin Hanbal, (Muassasatu al-Risa lah 2001 m), jilid 34, h. 319, dan Abu Bakar Ahmad bin Hu sein al-Baihaqi, Sunan al-Shogir li alBaihaqi, (Jamiah a l-Dirosah al-Islamiah Pa kistan 1989 m), Cet ke-1, jilid 3, h. 345, Abu Muhammad alHusein bin Mas e ud al-Baghowi, Syarh al-Sunnah, (al-Maktabah al-Islamiah Dimaskus, Bairut 1983 m), Cet ke-2, jilid 12, h. 110
} 
artinya "Bahwa Nabi saw pernah berkata kepada seorang wanita juru khitan anak perempuan yang biasa dipanggil Ummu atiyah"14: "Lakukanlah khitan dan jangan berlebihan (potonglah sedikit dengan ringan), karena kalau hanya memotong sedikit (tidak berlebihan), dapat menjadikan wajah lebih ceria dan disukai suami”. (HR. alHakim, al-Thabarany, al-Baihaqi) ${ }^{15}$.

Menurut Imam Nawawi, usia untuk berkhitan tidak ditentukan secara khusus dan tegas oleh syara ${ }^{e}$. Dianjurkan mengerjakan khitan itu selekas mungkin, bahkan sebaiknya hari ketujuh sesudah lahir, jika dianggap bayi tidak akan mendapat bahaya karena itu, seperti yang dilakukan di Timur Tengah. Beliau menuliskan didalam kitabnya Minhaj at-Thalibin wa Umdatu al-Muftīn fi al-Fiqh: “Wajib bagi perempuan berkhitan, dengan memotong sebagian daging kecil yang berada di bagian atas kemaluan, dan bagi laki-laki dengan menghilangkan sebagian kulit penutup bagian depan dari kemaluan, dan disunnahkan bagi laki-laki untuk menyegerakan khitan di umur tujuh tahun"'16.

Begitu juga yang ada dalam tradisi masyarakat Islam Indonesia, terutama bagi anak laki-laki, keluarga muslim biasanya mengkhitan anaknya yang pria pada usia tingkat sekolah dasar, yakni sekitar usia 6-12 tahun ${ }^{17}$. Sekarang ini semakin marak isu dan pembicaraan tentang khitan bagi perempuan, baik lewat media cetak dan elektronik, maupun melalui kajian. Dalam masalah ini terdapat dua pendapat yang pro dan kontra. Menurut Mazhab Syafiei, khitan wajib hukumnya baik laki-laki maupun perempuan. Pendapat ini didasarkan pada hadis dari Abu Hurairah, bahwa Rasulullah SAW "jika sudah bersatuke empat paha, dan bersentuhan dua barangyang dikhitan,

\footnotetext{
${ }^{14}$ Huzaemah Tahido Yanggo, Hukum Keluarga Dalam Islam, (Jakarta:Yayasan Masyarakat Indonesia Baru, 2013), h. 65

${ }^{15}$ Abu al-Qasim al-Tobroni, Mu 'jam al-Kabir, (Maktabah Ibnu al-Tamimiyah, Kairo), Cet ke-2, jilid 8, h. 299, dan Suhaib Abdul al-Jabbar, al-Jami' al-Shohih li al-Sunan wa al-Asanid, jilid 24, h. 190. Lihat juga Abu Bakar Ahmad bin Husein al-Baihaqi, Sunan al-Shogir li al-Baihaqi, (Jamiah al-Dirosah alIslamiah Pakistan 1989 m), Cet ke-1, jilid 3, h. 344

${ }^{16}$ Abu Zakaria Yahya Bin Syarif al-Nawawi, Minhaju al-Thalibin wa Umdatulal-Muftin, (Daarul Minhaj 2008), jilid 1, h. 306

${ }^{17}$ Setiawan Budi Utomo, Fiqih Aktual:Jawaban Tuntas Masalah Kontemporer, (Jakarta: Gema Insani Press, 2003)h.303

18 Ahmad lutfi Fathullah, Fiqh Khitan Perempuan (Jakarta:al-Mughnidan Mitra Inti, 2006), h. 30
} 
maka sudah dijatuhkan kewajiban mandi. "(HR. Bukhari-Muslim, al-Nasai, Ahmad, dan Baihaqi) ${ }^{18}$.

Sedangkan Mazhab Hanbali, hukum khitan wajib atas laki-laki dan makrumah (kemuliaan) bagi perempuan sehingga tidak wajib atas mereka. Apabila seseorang yang telah dewasa masuk Islam kemudian dia takut jika dikhitan (akan membahayakan kesehatan dan jiwanya) maka ia terlepas dari kewajiban di khitan. Namun, jika orang tersebut tadi percaya akan tidak adany a hal yang membahyakan kesehatan dan jiwanya, maka ia harus melakukannya ${ }^{19}$.

Mazhab Hanafi dan Mazhab Maliki, pendapat kedua mazhab ini pada dasarnya sama mengenai khitan, yakni khitan laki-laki hukumnya sunnah dan hukum khitan bagi perempuan hukumnya makrumah. Hal ini didasarkan pada hadis yang berbunyi: "dari Dlahhak bin Qais, ia berkata: Dahulu di Madinah ada seorang wanita yang biasa mengkhitan anak-anak perempuan, ia bernama Ummu Athiyah. Maka Rasulullah SAW bersabda kepadanya, "Khitan kan lah, dan jangan kamu habiskan, karena yang demikian itu lebih mencerahkan wajah, dan lebih menyenangkan suami”. (HR. Hakim $)^{20}$.

Sedangkan jumhur ulama mengatakan bahwa khitan laki-laki hukumnya wajib sedangkan perempuan hukumnya makrumah (kemuliaan) atau diperbolehkan, yang tujuannya untuk memuliakan perempuan. Pendapat yang pro dengan khitan anak perempuan sepakat mengatakan, bahwa khitan anak perempuan itu diperbolehkan dan merupakan bagian dari ajaran Islam. Mereka berbeda pendapat hanya dalam menentukan hukumnya wajib, sunnah, atau makrumah. Sedangkan pendapat yang

\footnotetext{
${ }^{18}$ Abu Abdillah Muhammad bin Ismail al-Bukhori al-ju "efi, al-Jami al-Shohih, (Da arut Tuq an-Najat 1422 H) Cetke-1. Jilid 1, h. 66, da n Abu al-Hasan Muslim bin al-Hajaj al-Qusyairi an-Nisaburi, al-Jami al-Shohih, (Darul Ihyait Turos Bairut). Jilid 1, h. 271, dan Abu Abdurahman Ahmad bin Syueib alKhurosani, al-Mujtaba Minal-Sunan, (Maktabah al-Matbueah al-Islamiah 1986m), Cet ke-2, jilid 1, h. 110, dan Abu Abdillah Ahmad bin Muhammad bin Hanbal, Musnad al-Imam Ahmad bin Hanbal, (Muassasatu al-Risalah 2001 m), jilid 12, h. 126, dan Abu Bakar Ahmad bin Husein al-Baihaqi, alSunanu al-Kubro li al-Baihaqi, (Daaru al-Kutub al-Ilmiah Bairut, Libanon 2003 m), jilid 1, h. 252

${ }^{19}$ Setia wan Budi Utomo, Fiqih Aktual:Jawaban Tuntas Masalah Kontemporer, (Jakarta: Gema Insani Press, 2003), h. 304

${ }^{20}$ Abu al-Qasim al-Tobroni, Mu'jamal-Kabir, (Maktabah Ibnu al-Tamimiyah, Kairo), Cet ke-2, jilid 8, h. 299, dan Suhaib Abdul al-Jabbar, al-Jami' al-Shohihli al-Sunan wa al-Asanid, jilid 24, h. 190. Lihat juga Abu Bakar Ahmad bin Husein al-Baihaqi, Sunan al-Shogir li al-Baihaqi, (Jamiah al-Dirosah alIslamiah Pakistan 1989 m), Cet ke-1, jilid 3, h. 344
} 
kontra mengatakan, bahwa khitan anak perempuan itu, hanya tradisi, bukan dari ajaran Islam dan mendatangkan mudharat serta melanggar HAM anak perempuan ${ }^{21}$.

Adapun upacara perayaan khitan yang lazim dikenal sebagai walimah khitan tasyakuran atau sunatan dan biasanya diiringi dengan acara keagamaan yang bernuansa Islam, pengajian dan sedekahan yang menguraikan hikmah serta konsekuensi khitan itu dilakukan untuk mensyiarkan sunnah khitan. Walimah khitan sebenarnya tidak ada perintah atau larangan dalam agama Islam, namun hal ini dapat dikembalikan kepada kaidah fiqih yang mengatakan,"Pada dasarnya segala sesuatu itu dibolehkan selama tidak ada dalil yang melarangnya, dan sebagaimana kaidah fiqih yang mengatakan bahwa sesuatu yang eksis karena tradisi yang baik (urf) yang tidak bertentangan dengan syariat) dapat menjadi kelaziman karena ketentuan syara "e "Namun yang perlu dijaga adalah perayaan yang dilakukan tersebut tidak berlebihan, tidak mempertontonkan aurat anak yang dikhitan kepada khalayak, dan tidak melangsungkan acara yang bertentangan dengan prinsip syariah ${ }^{22}$.

Khitan perempuan pada masyarakat Indonesia pun dilakukan dengan beragam cara. Diantaranya, dengan memotong sedikit atau melukai sebagian kecil alat kelamin bagian luar atau ujung klitoris. Adapun Khitan atau sunat perempuan yang dilakukan oleh masyarakat Kabupaten Bogor pada umumnya didasarkan oleh tradisi dan budaya masyarakat yang diwarisi secara turun-temurun dan diperkuat dengan ajaran-ajaran agama terutama agama Islam. Khitan perempuan masih dilestarikan oleh masyarakat sampai saat ini karena adanya keyakinan, ketundukan terhadap norma-norma dan adanya niat dari masyarakat untuk melaksanakan praktek khitan tersebut.

Salah satu masyarakat Kabupaten Bogor yang masih mempraktekkan khitan pada perempuan adalah masyarakat Desa Rawakalong dan menyebutnya sebagai "kekerikan"23. Desa Rawakalong merupakan salah satu desayang beradadi Kecamatan Gunung Sindur Kabupaten Bogor. Jumlah penduduknya keseluruhan 10,426 jiwa adapun laki-laki 5,080 jiwa dan perempuannya ada 5.346 jiwa dan desa rawakalong

\footnotetext{
${ }^{21}$ Huzaemah Tahido Yanggo, Hukum Keluarga Dalam Islam, (Jakarta:Yayasan Masyarakat Indonesia Baru, 2013), h. 65

${ }^{22}$ Setia wan Budi Utomo, Fiqih Aktual:Jawaban Tuntas Masalah Kontemporer, (Jakarta: Gema Insani Press, 2003), h. 303-306

${ }^{23}$ Ibu Era, Dukun Bayi Di Desa Rawakalong, Wawancara Pribadi, Rawakalong, 29 Maret 2019, jam 09.00 WIB s/d selesai, di Rumah Ibu Era
} 
mempunyai Empat dusun di desanya salah satuny a dusun rawakalong, disini yang kami teliti hanya dusun rawakalong saja dengan jumlah penduduknya 2,891 jiwa, jumlah laki-lakinya 1,308 jiwa dan perempuanya 1.583 jiwa $^{24}$.Masyarakat desa tersebut dikenal sebagai masyarakat yang taat dan patuh terhadap ajaran-ajaran agama Islam dimana mayoritas penduduknya beragama Islam. Dari keseluruhan warga desa tersebut 2.891 jiwa, yang beragama islam 99,38\%, sedangkan yang non islam 0,62\%. Selain patuh terhadap ajaran agama masyarakat desa tersebut juga berpegang teguh terhadap tradisi dan adat istiadat, salah satunya yaitu khitan pada perempuan atau masyarakat tersebut sering menyebutnya dengan “kekerikan”. Tradisi yang sudah dilaksanakan secara turun menurun tersebut sampai sekarang masih dilaksanakan.

Masyarakat Desa Rawakalong menganggap bahwa khitan perempuan (kekerikan) sama hukumnya dengan khitan pada laki-laki yaitu wajib untuk dilaksanakan, sehingga hampir setiap anak laki-laki maupun perempuan di Desa tersebut pasti dikhitan. Berdasarkan hasil wawancara peneliti terhadap salah satu informan yang merupakan masyarakat Desa Rawakalong, menjelaskan:Khitan perempuan itu merupakan tradisi yang sudah ada sejak zaman dahulu dan dilakukan oleh masyarakat sini secara turun menurun, sampai sekarang pun masyarakat sini masih melaksanakan tradisi tersebut. Seperti halnya khitan pada laki-laki bahwa khitan perempuan di masyarakat Desa Rawakalong masih dilaksanakan, hanya saja tata cara pelaksanaanya berbeda ${ }^{25}$.

Dari uraian di atas penelitian ini menjadi menarik untuk dibahas karena khitan yang dilakukan oleh laki-laki dan perempuan berbeda. Di setiap daerah mempunyai cara tersendiri dalam melaksanakan khitan pada perempuan. Salah satu contohnya adalah Desa Rawakalong, Kecamatan Gunung Sindur Kabupaten Bogor, cara melaksanakannya sama dengan Desa Pakis Kecamatan Gunung Sindur Kabupaten Bogor yaitu dengan meletakan koin di bawah klitoris dan menoreh bagian putih selaput klitoris tersebut dengan pisau lepit, Sedangkan yang berbeda misalnya Desa Pengasinan hanya mencolek ujung klitoris dengan jarum.

\footnotetext{
${ }^{24} 26$ sumber data kependudukan Desa Rawakalong "Profil Desa Rawakalong Tahun 2018"

${ }^{25}$ Ibu Amalia, Sesepuh Desa Rawakalong, Wawancara Pribadi, Rawakalong, 29 Maret 2019, jam16.30 WIB s/d selesai, di rumah Ibu Amalia
} 


\section{METODOLOGI}

Dalam penelitian ini penulis menggunakan penelitian yang bersifat kualitatif yaitu suatu pendekatan penelitian yang menghasilkan data deskriptif bertujuan untuk menggambarkan keadaan atau status fenomena dalam situasi tertentu dengan melakukan penelitian lapangan (Field Research) untuk mendapatkan data-data lapangan yang berhubungan dengan permasalahan yang akan dikaji dalam penelitian. Disamping menggunakan penelitian langsung juga menggunakan buku buku yang berhubungan dengan masalah yang di hadapi. Dalam penelitian ini menggambarkan dan menguraikan tentang kontruksi Sosial Budaya Praktek Khitan Pada Perempuan dalam Prespektif Hukum Islam di Desa Rawakalong Kecamatan Gunung Sindur Kabupaten Bogor. Dengan demikian seorang peneliti lapangan dalam memperoleh data yang diperlukan harus turun ke lapangan untuk memperoleh data yang lengkap.

Lokasi penelitian ini berada di Desa Rawakalong Kecamatan Gunung Sindur Kabupaten bogor. Alasan pemilihan di Desa Rawakalong karena masyarakatnya sampai sekarang masih melaksanakan tradisi yang telah berlangsung secara turuntemurun yaitu khitan pada perempuan yang mana di desa tersebut khitan wanita biasa disebut kekerikan.

Sumber data primer dapat diperoleh melalui observasi, wawancara dan dokumentasi, peneliti melakukan wawancara dengan pihak-pihak yang mengetahui objek yaitu Kepala Desa (Kadus), para tokoh agama, dan anggota masyarakat yang bersangkutan agar di dapatkan informasi atau data-data yang berkaitan dengan judul penelitian yang diambil secara langsung dari objek penelitian tersebut. Sumber data Sekunder adalah catatan atau dokumentasi perusahaan, publikasi pemerintah, ana lisis industri oleh media, situsweb, internet dan seterusnya ${ }^{26}$ data yang sifatnya mendukung keperluan data primer ${ }^{27}$.

Adapun pengumpulan data yang digunakan penulis dalam penelitian ini yaitu sebagai berikut: Wawancara; Dokumentasi; Observasi

Menurut miles Huberman, kegiatan analisis terdiri dari tiga alur kegiatan yang terjadi secara bersamaan, yaitu reduksi data, penyajian data, dan penarikan

\footnotetext{
${ }^{26}$ Uma Sekaran, metodepenelitian untukbisnis, (Jakarta: Salemba Empat, 2006), h. 104

${ }^{27}$ Sugiyono, Metode Penelitian Kuantitatif Kualitatif dan R\&D, (Bandung: Alfabeta, 2008), h. 301
} 
kesimpulan/verivikasi. Terjadi secara bersamaan berarti reduksi data, penyajian data, dan penarikan kesimpulan/ verivikasi sebagai sesuatu yang saling jalin menjalin merupakan proses siklus dan interaksi pada saat sebelum, selama, dan sesudah pengumpulan data dalam bentuk sejajar yang membangun wawasan umum yang disebut analisis teknik analisis data yang digunakan dalam penelitian kualitatif mencakup Transkip hasil wawancara, reduksi data, analisis, interpretasi data Dan triangulasi Dari hasil analisis data yang kemudian dapat ditarik kesimpulandan

\section{GAMBARAN UMUM DESA RAWAKALONG KECAMATAN GUNUNG SINDUR KABUPATEN BOGOR}

Desa Rawakalong merupakan salah satu desa di wilayah kecamatan gunung sindur kabupaten bogor, dengan luas wilayah $525 \mathrm{ha}$, di atas permukaan laut $125 \mathrm{M}$, dan tinggi curah hujan 2.004 M3, yang terdapat dalam 4 dusun, salat satunya dusun Rawakalong yaitu memiliki 8 RW dan 23 RT, singkat cerita Desa Rawakalong lebih tepatnya terletak diantara rawa-rawa dan perkebunan, dan kalong itu sendiri kebanyakan masyarakat Desa Rawakalong pada Zaman dahulu itu mencari nafkah atau mencari mata pencaharianya di luar desa itu sendiri seperti Jakarta dan sekitarnya disebutlah istilah kalong, dan inilah sejarah singkat asal muasal kenapa desa tersebut diberi nama desa "RAWAKALONG" Jadi Desa Rawakalong Kecamatan Gunung Sindur Kabupaten Bogor yang penulis teliti ini terletak di tepi jalan raya sehingga akses jalan menuju tempat tersebut tidak ada hambatan. Desa tersebut memiliki masyarakat yang beragam. Kebanyakan bermata pencaharian petani. Dalam pemahaman agama pun masyarakat setempat juga memiliki beragam pemahaman ada yang beraliran NU dan Muhammadiyah.

\section{PANDANGAN ULAMA DAN HUKUM ISLAM TENTANG KHITAN}

Para ulama memang berbeda pendapat tetang hukum khitan. Akan tetapi, mereka sepakat, bahwa khitan telah disyariatkan, baik untuk laki-laki maupun perempuan. Berikut ini pendapat para ulama tentang hukum khitan, sebagimana yang telah dikemukakan oleh Dr. Sa aed al-Masyafi dalam bukunya Ahadis al-Khitan Hujjiyatuha wa Fiqhuha.

\section{Khitan untuk laki-laki}


Para pengikut madzahab Hanafi berpendapat, bahwa khitan hukumnya sunnah untuk laki-laki. Mereka menganggap khitan sebagai salah satu bentuk syiar Islam seperti halnya adzan. Para pengikut Imam Malik juga memandang, bahwa khitan untuk laki-laki adalah sunnah. Menurut Imam Malik di dalam kitab al-Muntaqa Syarah alMuwath tha ${ }^{e e}$ Ibnu Abdil Barr di dalam kitab al-Kafi, dan Syekh Alaisi didalam kitab Manhul Jalil, pendapat tersebut merupakan pendapat tersebut merupakan pendapat yang terkuat dalam Madzhab Maliki. Dan didalam kitab al-Talqin juga disebutkan, bahwa hukum khitan adalah sunnah, bukan wajib ${ }^{28}$.

Sedangkan sebagian besar ulama ahli fikih pengikut Imam Syafi"e i berpendapat, bahwa khitan wajib untuk laki-laki. Imam Nawawi berkata, "Ini adalah pendapat yang shahih dan masyhur yang ditetapkan oleh Imam Syafie i dan telah disepakati oleh sebagian besar ulama. "Memang ada pula yang berpendapat, bahwa khitan itu sunnah untuk laki-laki, tetapi Imam Nawawi menolak pendapat tersebut ${ }^{29}$.

Dalam kitab Al-Majmue diungkapkan, mayoritas ulama salaf berpendapat, bahwa hukum khitan itu wajib. Menurutal-Khitabi, Ibnu Qayyim berkata, “Asy-Syae "bi, Rabieeah, al-Auzai, dan Yahya bin Sa ${ }^{e e}$ id al-Anshari berpendapat bahwa hukum khitan adalah wajib." Selain itu, dalam kitab Fathul Bari disebutkan, bahwa yang berpendapat khitan itu wajib dari kalangan ulama salafa dalam Imam al-Athae ila berkata, "Apabila orang dewasa masuk Islam, belum dianggap sempurna Islamnya sebelum dikhitan. Dan terakhir, para ulama Madzhab Hanbali juga berpendapat, bahwa hukum khitan wajib untuk laki-laki ${ }^{30}$.

Dari uraian di atas, tampak bahwa pendapat para fukaha tersebut secara umum dapat dipilih menjadi dua. Pertama, pendapat yang menyatakan bahwa hukum khitan itu wajib bagi laki-laki, pendapat ini merupakan pendapat Mazhab Hanbali, pendapat yang shahih dan masyhur dari pengikut Imam Syafiee i pendapat Sya ${ }^{e e}$ bi, Rabieah alAuzai, Yahya bin Sa ${ }^{e e}$ id al-Anshari, dan Imam al-Atha"eila.

\footnotetext{
${ }^{28}$ Achmad Ma"eruf Asrori, (Ber-Khitan Akikah Kurban Yang Benar Menurut Ajaran Islam, Surabaya:AlMiftah 1998), h.16

${ }^{29}$ Achmad Ma"eruf Asrori, (Ber-Khitan Akikah Kurban Yang Benar Menurut Ajaran Islam, Surabaya:AlMiftah 1998), h.16

${ }^{30}$ Achmad Ma"eruf Asrori, (Ber-Khitan Akikah Kurban Yang Benar Menurut Ajaran Islam, Surabaya:AlMiftah 1998), h.16
} 
Ada beberapa hal yang mereka jadikan alasan atau dalil kenapa khitanitu wajib, antara lain adalah sebagi berikut:

a. Khitan disyariatkan bagi orang yang sudah baligh atau mendekati masa baligh, dan orang yang dikhitan diperbolehkan membuka serta melihatnya. Sementara itu menutup aurathukumnya wajib dan melihatnya adalah haram. Oleh karena itu, seandainya khitan itu tidak wajib, niscaya kita tidak diperbolehkan membuka dan melihat aurat orang yang dikhitan, karena hal itu akan merusak harga diri dan kehormatannya. Orang yang pertama kali mengemukakan alasan ini adalah Abdul Abbas bin Suraji, lalu Imam alKhitabi, dan yang lainnya. Imam Nawawi menemukan pendapat ini dalam kitab alWada"e karya Ibnu Suraji, lalu ia berkata,"Saya tidak tahu, bahwa beliau juga berpendapat demikian." 31 .

b. Imam Nawawi mengungkapkan, bahwa Abu Ishaq al-Syirazi bersandar pada kitab Fi al-Khilaf dan Imam al-Ghazali pada kitab al-Wasith dengan cara melakukan qiyas. Mereka berkata, "Khitan adalah memotong sebagian anggota badan. Seandainya khitan tidak wajib, maka kita tidak boleh melakukannya, sebagimana kita tidak diperbolehkan memotong jari-jari kita. Tetapi memotong jari-jari bisa menjadi wajib karena qisas. "Didalam kitab Fathul Bari, Ibnu Hajar juga melakukan qiyas. Ia mengatakan, bahwa khitan adalah memotong anggota badan dengan niat ibadah, sehingga hal itu hukumnya wajib seperti hal nya memotong tangan pencuri ${ }^{32}$.

c. Menurut Imam al-Mawardi, pemotongan anggota badan akan menimbulkan akibat pada diri seseorang berupa penyakit. Oleh karena itu, tidak disyariatkan memotong anggota badan selain dalam tiga perkara: untuk kemaslahatan, karena hukum, atau karena suatu kewajiban yang harus dipenuhi. Dan khitan termasuk dalam kategori yang ketiga. al-Khitabi juga mengatakan, bahwa khitan itu wajib karena termasuk salah satu syiar agama. Dengan khitan itulah kita bisa membedakan dengan orang muslim dan non muslim. Jika dalam suatu peperangan kita menemukan jenazah seseorang yang telah dikhitan diantara beberapa jenazah yang belum dikhitan maka kita akan bisa memastikan bahwa orang itu beragama islam, sehingga kita akan mengurus jenazahnya

\footnotetext{
${ }^{31}$ Achmad Maeeruf Asrori, (Ber-Khitan Akikah Kurban Yang Benar Menurut Ajaran Islam, Surabaya:AlMiftah 1998), h.16

${ }^{32}$ Achmad Ma"e ruf Asrori, (Ber-Khitan Akikah Kurban Yang Benar Menurut Ajaran Islam, Surabaya:AlMiftah 1998), h.16
} 
sesuai dengan aturan islam. Demikian pula halnya dengan Ibnu al-Qayyim. Ia mengatakan, bahwa khitan adalah syie ar yang nyata sebagai pembeda antara seorang muslim dan non muslim. Kewajiban khitan tersebut lebih utama dari pada kewajiban melakukan shalat witir, kewajiban membayar zakat kuda, kewajiban mengulang wudhu (bagi orang yang tertawa terbahak-bahak ketika shalat), kewajiban berwudhu setelah berbekam, kewajiban tayamum sampai kedua siku, dan sebagainya. Bahkan hampirhampir kaum muslimin menganggap orang yang belum dikhitan termasuk golongan mereka. Para ulama ahli fikih mewajibkan orang islam yang dewasa agar berkhitan, meskipun kadang-kadang mengandung resiko ${ }^{33}$.

d. Al-Baihaqi mengatakan, bahwa dasar paling baik yang menunjukkan kewajiban khitan adalah hadis yang bersumber dari Abu Hurairah R.A.: "Nabi Ibrahim berkhitan dalam usia 80 tahun dengan memakai kampak. "34

Menurut Imam Nawawi, ayat ke 123 surat al--Nahl memerintahkan kepada kita untuk mengikuti syariat Nabi Ibrahim A.S. Hal itu menunjukkan, bahwa segala ajaran beliau wajib kita ikuti, kecuali ada dalil yang menyatakan hal tersebut sunah, seperti bersiwak dan lain-lain.

Kedua, adalah pendapat yang menyatakan bahwa khitan itu hukumnya sunnah. Pendapatini merupakan pendapat para pengikut Imam Hanafi, termasuk pendapat yang kuat dalam Mazhab Imam Malik, dan penadapat sebagian dari pengikut Imam Syafiei. Hal ini diungkapkan oleh Ibnu Abi Musa dari sahabat-sahabat Imam Ahmad dan Hasan al-Bashri ${ }^{35}$.

Alasan mereka yang berpendapat bahwa hukum khitan itu sunnah adalah sebagai berikut:

a. Adanya hadis yang menyatakan bahwa khitan itu sunah, bukan wajib, yang diriwayatkan dari Hajjaj, dari Abul Malih bin Utsama, dari ayahnya, bahwa Nabi SAW

\footnotetext{
${ }^{33}$ Achmad Ma"eruf Asrori, (Ber-Khitan Akikah Kurban Yang Benar Menurut Ajaran Islam, Surabaya:AlMiftah 1998), h.16

${ }^{34}$ Ibnu Qayyim AlJauziah, Tuhfatul Maudud bi Ahkamil Maulud, (Sudan:Maktabah Qa yyimah,1350), h. 89

${ }^{35}$ Achmad Ma"eruf Asrori, (Ber-Khitan Akikah Kurban Yang Benar Menurut Ajaran Islam, Surabaya:AlMiftah 1998), h.21
} 
bersabda ${ }^{36}$ : "Khitan itu sunah untuk laki-laki dan dianggap baik untuk wanita." (H.R. Ahmad, Baihaqi, dan Baghowi) ${ }^{37}$.

Akan tetapi, menurut Ibnu Hajar, Hajjaj adalah seorang pemalsu (mudallis) dan hadisnya mengandung kejanggalan. Kadang-kadang ia meriwayatkan hadist itu seperti di atas, tapi terkadang ada tambahan Syaddad bin Aus setelah ayahnya Abul Malih. Selanjtunya Ibnu Hajar mengatakan berkenaan dengan hadis itu ada riwayat lain yang tidak melalui jalur Hajjaj, yaitu yang telah diriwayatkan oleh Thabrani didalam buku al-Kabir dan Baihaqi didalam hadis Ibnu Abbas yang marfu ${ }^{e e}$. Namun menurut Baihaqi, hadist yang dimaksud sanadnya lemah, dan lebih condong mauquf ${ }^{38}$.

b. Adanya hadis yang diriwayatkan oleh Bukhari Muslim dan Nabi SAW. Yang menjelaskan tentang masalah fitrah yang lima, mereka berkata "Di dalam hadis tersebut Nabi SAW Mensejajarkan khitan dengan memotong kumis, mencabut bulu ketiak, memotong bulu kemaluan, dan memotong kuku, sehingga tidak diragukan lagi bahkan khitan bukan perkara wajib.

c. Pengikut Madzhab Hanafi berpendapat, bahwa khitan itu termasuk salah satu bentuk syiee ar Islam. Dan tidak semua halyang termasuk syiee ar Islam itu wajib. Selain ada yang wajib, seperti shalat, puasa, dan haji ada pula yang mustahab seperti membaca talbiyah, mengiring hewan ke tempat penyembelihan waktu haji, dan ada juga yang masih diperselisihkan hukumnya seperti adzan, shalat ied, memotong hewan kurban, dan khitan.

d. Hasan Al-Bashri berakata."Nabi SAW telah mengislamkan banyak orang kulit hitam, kulit putih, bangsa Parsi, Romawi, dan Habasyah. Beliau tidak pernah menanyakan apakah mereka berkhitan atau tidak dan saya tidak pernah mendengar bahwa Nabi SAW memeriksa mereka."39

\footnotetext{
${ }^{36}$ Setia wan Budi Utomo, Fiqih Aktual: Jawaban Tuntas Masalah Kontemporer, (Jakarta: Gema Insani Press,2003), h. 303

${ }^{37}$ Abu Abdillah Ahmad bin Muhammad bin Hanbal, Musnad al-Imam Ahmad bin Hanbal, (Muassasatu al-Risalah 2001 m), jilid 34, h. 319, dan Abu Bakar Ahmad bin Husein al-Baihaqi, Sunanal-Shogir li alBaihaqi, (Jamiah al-Dirosah al-Islamiah Pa kistan 1989 m), Cet ke-1, jilid 3, h. 345, Abu Muhammad alHusein bin Mas"ud al-Baghowi, Syarh al-Sunnah, (al-Maktabah al-Islamiah Dimaskus, Bairut 1983 m), Cet ke-2, jilid 12,h. 110

${ }^{38}$ Achmad Mae'aruf Asrori, (Ber-Khitan Akikah Kurban Yang Benar Menurut Ajaran Islam, Surabaya:AlMiftah 1998), h. 22

39 Achmad Ma"earuf Asrori, (Ber-Khitan Akikah Kurban Yang Benar Menurut Ajaran Islam, Surabaya:Al-Miftah 1998), h. 22
} 
Imam Bukhari meriwayatkan dalam kitab al-Adabul Mufrad, bahwa Salimbin Ubay al-Dzayyal berkata, "Saya mendengar al-Hasan berkata,"Mengapa kalian tidak merasa heran terhadap orang ini? (yang dimaksud adalah Malik bin al- Mundzir). Ia mendatangi beberapa orang tokoh masyarakat Kaskir yang kebanyakan berprofesi sebagai buruh tani. Mereka lalu memeluk Islam. Ketika Malik bin Mundzir menyuruh berkhitan, maka mereka pun berkhitan. Namun akibatnya, saat musim dingin tiba, saya mendengar sebagian dari mereka meninggal dunia. Padahal, ketika Nabi SAW mengislamkan orang Romawi, Habsyi, dan lain-lain, beliau tidak menanyakan apakah mereka berkhitan atau tidak."

Dari berbagai pendapat tersebut, kami cenderung untuk berpendapat bahwa khitan hukumnya wajib bagi laki-laki. Sebab, dalil-dalil yang mewajibkannya sangat kuat. Apabila sebagimana kita ketahui dalam pelaksanaan khitan, aurat harus terbuka dan orang yang mengkhitan jelas melihatnya bahkan memegangnya. Kalau bukan karena wajibnya khitan, hal itu tentu tidak dipebolehkan, karena hukum menutup aurat adalah wajib.

\section{Khitan untuk Perempuan}

Mazhab Hanafi berpendapat bahwa khitan untuk wanita dipandang baik ${ }^{40}$. Ada juga yang mengatakan hukumnya sunah, seperti yang diterangkan didalam kitab Fathul Qadir. Al-Bazazi juga berpendapat demikian. Jika orang banci saja perlu dikhitan apalagi wanita. Jika khitan wanita hanya dipandang baik, tentu orang banci tidak perlu dikhitan karena boleh jadi ia adalah seorang wanita. Sementara menurut mazhab Maliki, khitan bagi wanita dipandang baik. Dalam kitab Muntaqa (yang dikutip dari kitab al-Muwatha), diterangkan bahwa Imam Malik berkata, "Hendaklah seorang perempuan membiasakan diri memotong kuku, memotong bulu kemaluan, dan berkhitan, sebagaimana yang dilakukan laki-laki. Lain halnya dengan mazhab Sayafie i, Imam Syafiee $i$ dan para pengikutnya berpendapat, bahwa hukum khitan bagi wanita adalah wajib ${ }^{41}$. Imam Nawawi berkata dalam kitab al-Majmue,"menurut kami dan mayoritas ulama, berkhitan adalah wajib bagi laki-laki dan perempuan. Al-Khathabi

\footnotetext{
${ }^{40}$ Aini Aryani, Lc, Khitan Bagi Wanit, Haruskah?, (Rumah Fiqih Publishing, Setiabudi: Jakarta Selatan), h. 17

${ }^{41}$ 100HuzaemahTahidoYanggo, Hukum Keluarga Dalam Islam, (Jakarta:Yayasan Masyarakat Indonesia Baru, 2013),h. 58
} 
menghikayatkan cerita ini. Begitu pula Imam Ahmad mewajibkan khitan.”Dalam perkataan akhirnya, Imam Nawawi berkata, "pendapat yang shohih dan terkenal menurut Imam Syafiec $i$ dan ketetapan para ulama menegaskan tentang wajibnya khitan bagi laki-laki maupun perempuan. ${ }^{42}$ "

Sedangkan dalam Mazhab Hanbali belum ada kata sepakat tentang hukum khitan bagi wanita. Ada yang mengatakan hukumnya wajib, sebagaimana dijelaskan dalam kitab Syahrul Muntahal Iradat ${ }^{43}$. Tetapi Ibnu Qudamah berpendapat, bahwa khitan wanita hanya dipandang baik dan hukumnya tidak wajib.

Menurut Imam Ahmad, adanya ketentuan yang menyatakan wajibnya mandi apabila dua bagian yang dikhitan saling bertemu menunjukkan, bahwa sejak dulu telah banyak wanita yang berkhitan ${ }^{44}$. Dari uraian diatas, tampak bahwa pendapat para fuqaha tentang hukum khitan bagi wanita dapat dikelompokkan menjadi tiga.

Pertama, pendapat yang menyatakan, bahwa hukum khitan bagi wanita adalah wajib. Ini adalah pendapat yang shahih dan masyhur dari pengikut Imam Syafie ${ }^{\text {ee }}$ dan Imam Hanbali. Dasarnya sama seperti kewajiban khitan bagi laki-laki. Mereka juga berdalil dengan fakta tentang diperbolehkannya membuka aurat untuk urusan berkhitan serta tidak diperbolehkanya memotong anggota badan kecuali untuk sesuatu yang hukumnya wajib.

Disamping itu, mereka juga berdalil dengan hadis: "Apabila dua bagian yang dikhitan telah bertemu, maka telah mewajibkanadanya mandi. ${ }^{45}$ " Hal itu menunjukkan, bahwa pada zaman dahulu wanita telah berkhitan. Bahkan ada yang berkata,"Seorang laki-laki diperbolehkan memaksa istrinya untuk berkhitan seperti halnya memaksanya untuk mengerjakan shalat" 46 . Hal ini sebagaimana dalam kitabnya Minhaj at-Thalibin wa Umdatu al-Muftin fi al-Fiqh: "Wajib bagi perempuan berkhitan, dengan memotong

\footnotetext{
${ }^{42}$ Tim Riset Penerbit al-Qira “ah, Haqiqahal-Khitan Syar'iyyan wa Thibbiyyan, (Dar al-Qira "ah, Ka iro, Mesir 2007), h. 28

${ }^{43}$ Tim Riset Penerbit al-Qira "ah, Haqiqahal-Khitan Syar'iyyan wa Thibbiyyan, (Dar al-Qira "ah, Kairo, Mesir 2007), h. 28

${ }_{44}$ Achmad Ma"earuf Asrori, Ber-Khitan Akikah Kurban (Yang Benar Menurut Ajaran Islam, Surabaya:Al-Miftah 1998), h. 29
}

${ }^{45}$ M.Ali Hasan, (Masail Fiqhiyah Al-Hadisah: Pada Masalah-Masalah Kontemporer Hukum Islam, Jakarta:Raja Grafindo Persada 2003). h. 202

${ }^{46}$ Aini Aryani, Khitan Bagi Wanit, Haruskah?, (Rumah Fiqih Publishing, Setia budi: Jakarta Selatan), h. 16 
sebagian daging kecil yang berada di bagian atas kemaluan, dan bagi laki-laki dengan menghilangkan sebagian kulit penutup bagian depan dari kemaluan, dan disunnahkan bagi laki-laki untuk menyegerakan khitan di umur tujuh tahun"47.

Kedua, adalah pendapat yang mengatakan, bahwa khitan bagi wanita hukumnya sunah. Ini merupakan pendapat sebagian pengikut Imam Hanafi, Imam Malik, dan beberapa pengikut Imam Syafiei sebagimana dituturkan oleh al-Rafiee dan Imam Ahmad ${ }^{48}$. Imam al-Zaila ${ }^{e e}$ salah satu ulama Madzhab Hanafiyah dalam kitab Tabyin al-Haqaiq Syarh Kanzu al-Daqaiq menuiskan sebagai berikut "Tidaklah sunnah bagi perempuan berkhitan, tetapi sebuah kemuliaan bagi laki-laki, karena dapat menambah keintiman dalam hubungan suami-isteri" 49 .

Ketiga, adalah pendapat yang menyatakan, bahwa khitan bagi wanita hukumnya mukromah (dipandang baik). Pendapat ini dikemukakan oleh para pengikut Imam Hanafi, sebagian pengikut Imam Malik dan Imam Hanbali. Beberapa ulama lain juga berpendapat demikian dengan berdalil pada sebuah hadis:

"Khitan itu sunah untuk laki-laki dan dianggap baik untuk wanita." (H.R. Ahmad, Baihaqi, dan Baghowi) ${ }^{50}$. Demikian pula ada pendapat yang menyatakan, bahwa hukum khitan dipandang baik bagi anak perempuan tidak ada hadisnya, kecuali hadis tersebut diatas. Juga dari hadis yang berbunyi: "Apabila dua bagian yang dikhitan saling bersentuhan, telah mewajibkan adanya mandi”, menurut Imam Ahmad bisa diketahui, bahwa wanita muslimah pada zaman dahulu selalu berkhifadh.

Nabi Muhammad SAW juga pernah bersabda, “Apabila kamu berkhifadh, maka janganlah berlebihan, karena jika tidak berlebihan akan menjadikan wajah lebih ceria dan terasa lebih nikmat saat melakukan hubungan badan. "Hadis ini termasuk hadis hasan dan memberi syarat bahwa wanita muslimah pada masa Rasulullah SAW. Sudah

\footnotetext{
${ }^{47}$ Abu Zakaria Muhyiddin Yahya Bin Syaraf al-Nawawi, Minhaj al-Thalibin Wa Umdatu al-Muftin, (Beirut: Daral-Fikr, 1425H/2005 M), juz 1,h. 306

${ }^{48}$ Aini Aryani, Khitan Bagi Wanit, Haruskah?, (Rumah Fiqih Publishing, Setia budi: Jakarta Selatan), h. 15

${ }^{49}$ Fakhruddin Ustman Bin Alial-Zila "ial-Hanafi, Tabyinal-Haqaiq Syarh Kanzual-Daqaiq, (Ka iro: alMa tba"ahal-Kubro al-Amiriah) Cet ke-1, 1313 H, juz 6, h. 227

${ }^{50}$ Abu Abdillah Ahmad bin Muhammad bin Hanbal, Musnad al-Imam Ahmad bin Hanbal, (Muassasatu al-Risa lah 2001 m), jilid 34, h. 319, dan Abu Bakar Ahmad bin Hu sein al-Baihaqi, Sunan al-Shogir li alBaihaqi, (Jamiah al-Dirosah al-Islamiah Pa kistan 1989 m), Cet ke-1, jilid 3, h. 345, Abu Muhammad alHusein bin Mas"ud al-Baghowi, Syarh al-Sunnah, (al-Maktabah al-Islamiah Dimaskus, Bairut 1983 m), Cet ke-2, jilid 12, h. 110
} 
melaksanakan khifadh. Rasulullah SAW sendiri menunjukkan cara khitan yang baik sehingga tidak menimbulkan bahaya. Petunjuk Rasulullah SAW tersebut bisa dijadikan dasar bahwa hukum khitan bagi wanita adalah sunnah. Sebagaimana dinyatakan oleh Imam al-Syaukani, bahwa hukum khitan bagi wanita itu sunah adalah merupakan hal yang pasti, dan kita wajib berpegang pada yang pasti sampai ada dalil lain yang mengubahnya ${ }^{51}$.

Ibnu Qudamah salah satu ulama dari kalangan Madzhab Hanabilah di dalam kitabnya al-Mughni menuliskan sebagai berikut:52 "Diwajibkan bagi laki-laki berkhitan, sedangkan bagi perempuan tidaklah diwajibkan, melainkan hanya sebuah kemuliaan bagi yang mengerjakannya" 53 .

Dalam Islam terdapat beberapa cara dalam menentukan hukum suatu masalah yakni melalui pertimbangan Quran, Hadis, Ijma, dan Qiyas. Dalam Quran sendiri, tidak ada ayat yang menyinggung secara khusus tentang khitan bagi laki-laki maupun perempuan. Dengan demikian, dasar hukum khitan adalah bukan berlandaskan firman Allah SWT, akan tetapi berlandaskan dalil lain, yakni Hadist Rasulullah SAW. Ada beberapa hadis yang menjadi dasar khitan bagi perempuan, seperti hadist dari Abul Malih bin Usamah dari ayahnya bahwasannya Nabi SAW bersabda54: "Khitan itu disunnahkan bagi kaum laki-laki dan dimuliakan bagi kaum wanita (HR. Ahmad)",55.

Dari uraian di atas dapat kami simpulkan, bahwa pada umumnya para ulama sepakat mengatakan bahwa khitan itu suatu hal yang masyrue (disyariee atkan) baik bagi laki-laki ataupun perempuan. Sebagaimana yang dinukil Ibnu Hazam dalam bukunya Maratibul Ijma ${ }^{e e}$ dan Ibnu Taimiyah dalam bukunya Majmuee Al-fatawa ${ }^{56}$, hukum khitan bagi perempuan menurut mazhab al-Arba ${ }^{e e}$ ah sebagai berikut:

\footnotetext{
${ }^{51}$ Achmad Mae"ruf Asrori, Ber-Khitan Akikah Kurban Yang Benar Menurut Ajaran Islam, Surabaya:AlMiftah 1998), h. 30-32

${ }^{52}$ Aini Aryani, Lc, Khitan Bagi Wanit, Haruskah?, (Rumah Fiqih Publishing, Setiabudi: Jakarta Selatan), h. 18

${ }^{53}$ Abu Muhammad Abdullah bin Ahmad bin Qudamah al-Hanbali, al-Mughni li ibnial-Qudamah (Kairo: Maktabah al-Qahiro 1388 H/1968M), Juz 1, h. 64

${ }^{54}$ Hasan, M. Ali, Masail Fiqhiyah Al-Hadisah: Pada Masalah-Masalah Kontemporer Hukum Islam, (Jakarta:Raja Grafindo Persada 2003), h. 203

${ }^{55}$ Abu Abdillah Ahmad bin Muhammad bin Hanbal, Musnad al-Imam Ahmad bin Hanbal, (Muassasatu al-Risalah 2001 m), jilid 34, h. 319, dan Abu Bakar Ahmad bin Hu sein al-Baihaqi, Sunan al-Shogir li alBaihaqi, (Jamiah al-Dirosah al-Islamiah Pa kistan 1989 m), Cet ke-1, jilid 3, h. 345, Abu Muhammad alHusein bin Mas eud al-Baghowi, Syarh al-Sunnah, (al-Maktabah al-Islamiah Dimaskus, Bairut 1983 m), Cet ke-2, jilid 12, h. 110

${ }^{56}$ Akmal Abdul Munir, Hukum Khitan Wanita Menurut Hukum Islam, (Makalah. 2007), h. 2
} 
1. Mazhab Syafie $i$, khitan wajib hukumnya baik laki-laki maupun perempuan. Pendapat ini didasarkan pada hadist dari Abu Hurairah, Rasul bersabda yang artinya: Dari Abu Hurairah R.A., bahwasanya Rasulullah SAW bersabda ${ }^{57}$ : "jika sudah bersatu ke empat paha, dan bersentuhan dua barang yang dikhitan, maka sudah dijatuhkan kewajiban mandi. ”(HR. Bukhari-Muslim, al-Nasai, Ahmad, dan Baihaqi) ${ }^{58}$.

2. Mazhab Hanbali, hukum khitan wajib atas laki-laki dan makrumah bagi perempuan tidak wajib atas mereka. Apabila seseorang yang telah dewasa masuk Islam kemudian dia takut jika dikhitan (akan membahayakan kesehatan dan jiwanya) maka ia terlepas dari kewajiban dikhitan. Namun jika orang tersebut tadi percaya, maka ia harus melakukannya.

3. Mazhab Hanafi dan Mazhab Maliki, pendapat kedua mazhab ini pada dasarnya sama mengenai khitan, yakni khitan laki-laki hukumnya sunah dan hukum khitan bagi perempuan hukumnya makrumah. Hal ini didasarkan pada hadis yang yang berbunyi: “dari Dlahhak bin Qais, ia berkata: Dahulu di Madinah ada seorang wanita yang biasa mengkhitan anak- anak perempuan, ia bernama Ummu Athiyah. Maka Rasulullah SAW bersabda kepadanya, "Khitan kan lah, dan jangan kamu habiskan, karena yang demikian itu lebih mencerahkan wajah, dan lebih menyenangkan suami". (HR. Hakim) ${ }^{59}$.

Khitan adalah syiar kaum muslimin dan yang membedakan antara mereka dengan umat lainnya dari kalangan kaum kufar dan ahli kitab. Oleh sebab itu, sebagaimana syiar kaum muslimin yang lain wajib, maka khitan pun wajib. Juga sebagaimana menyelisihi kaum kuffar itu wajib, maka khitan juga wajib. Khitan itu wajib hukumnya bagi laki-laki dan makrumah bagi perempuan. Tetapi bagi laki-laki

\footnotetext{
${ }^{57}$ Ahma d lutfi Fa thullah, Fiqh Khitan Perempuan (Ja karta:al-Mughni dan Mitra Inti, 2006), h. 30

${ }^{58}$ Abu Abdillah Muhammad bin Ismail al-Bukhori al-ju ${ }^{e e}$ fi, al-Jami al-Shohih, (Da arut Tuq an-Najat 1422 H) Cetke-1. Jilid 1, h. 66, dan Abu al-Hasan Muslim bin al-Hajaj al-Qusyairi an-Nisaburi, al-Jami al-Shohih, (Darul Ihyait Turos Bairut). Jilid 1, h. 271, dan Abu Abdurahman Ahmad bin Syueib alKhurosani, al-Mujtaba Minal-Sunan, (Maktabah al-Matbư ah al-Islamiah $1986 \mathrm{~m}$ ), Cet ke-2, jilid 1, h. 110, dan Abu Abdillah Ahmad bin Muhammad bin Hanbal, Musnadal-Imam Ahmad bin Hanbal, (Muassasatu al-Risalah 2001 m), jilid 12, h. 126, dan Abu Bakar Ahmad bin Husein al-Baihaqi, alSunanu al-Kubro li al-Baihaqi, (Daaru a l-Kutub al-Ilmiah Bairut, Libanon 2003 m), jilid 1, h. 252

${ }^{59}$ Abu al-Qa sim al-Tobroni, Mu 'jam al-Kabir, (Maktabah Ibnu al-Tamimiyah, Kairo), Cet ke-2,jilid 8, h. 299, da n Suhaib Abdul al-Jabbar, al-Jami'al-Shohih li al-Sunan wa al-Asanid,jilid 24, h. 190. Lihat juga Abu Bakar Ahmad bin Husein al-Baihaqi, Sunan al-Shogir li al-Baihaqi, (Jamiah al-Dirosah alIslamiahPakistan 1989 m), Cet ke-1, jilid 3, h. 344
} 
lebih dianjurkan. Sedangkan bagi perempuan hanya merupakan suatu kehormatan (sunah/makrumah). Kata sunah yang dikehendaki di sini bukan berarti lawan kata wajib. Sebab kata sunah apabila dipakai dalam sebuah hadist, maka tidak dimaksudkan sebagai lawan kata wajib, namun lebih menunjukkan persoalan membedakan antara hukum laki-laki dan perempuan. Dengan begitu arti kata sunah dan kata makrumah adalah bahwa laki-laki lebih dianjurkan berkhitan dibanding perempuan.

Dengan demikian, kiranya dapat disimpulkan bahwa khifad hukumnya sunnah untuk perempuan meskipun ada yang berpendapat bahwa khifad itu wajib, namun tidak ada satu hadis pun yang kuat untuk dijadikan dasar. Yang ada hanya hadis yang mewajibkan khitan bagi anak laki-laki.

\section{TATA CARA PELAKSANAAN KHITAN PADA PEREMPUAN DI DESA RAWAKALONG}

Khitan laki-laki yang telah membudaya di berbagai belahan dunia, dilaksanakan dalam bentuk yang sama di semua tempat, yaitu pemotongan kulup penis (kulit kepala dzakar) laki-laki ${ }^{60}$. Sedangkan pelaksanaan khitan perempuan akan berbeda di setiap tempat bahkan Negara. Di Indonesia, prakteknya ada yang sekedar membasuh ujung klitoris, menusuk dan mencolek ujung klitoris dengan jarum, mencolek dengan kunyit, menggosok dengan batu permata, mengiris sebagian klitoris, bahkan sebagian lain memotong seluruh klitoris.

Di Desa Rawakalong khitan perempuan dijadikan tradisi sejak zaman dahulu oleh masyarakatnya, dan sampai sekarang pun khitan perempuan masih dilaksanakan. Biasanya usia untuk anak yang dikhitan itu setelah umur 35 hari sampai umur 5 tahun. Cara melaksanakan khitan perempuan di Desa Rawakalong dengan meletakan koin di bawah klitoris lalu menoreh selaput putih di bagian klitoris tersebut dengan menggunakan pisau kecil/pisau lipat. Sedangkan waktu untuk melaksanakan khitan

\footnotetext{
${ }^{60}$ Elga Serapung, Agama dan Kesehatan Reproduksi (Jakarta:Pustaka Sinar Harapan, 1999), h. 118
} 
perempuan biasanya usia 40 hari dari terhitung bayi lahir ke dunia 61 . Kekerikan (khitan perempuan) sampai sekarang masih dilaksanakan warga Desa Rawakalong, kekerikan biasanya dilakukan oleh dukun bayi. Biasanya orang tua yang datang ke rumah dukun bayi untuk meminta tolong agar anaknya di khitan.” Setelah itu orang tua menyiapkan semua perlengkapan yang akan digunakan untuk mengkhitan:

“Orang tua yang mau mengkhitan anaknya harus menyiapkan peralatan yang akan digunakan, contohnya kain putih, koin dan pisau lipat.

Adapaun proses sebelum melaksanakan khitan perempuan, yaitu:

1. Tahap persiapan

Sebelum melaksanakan khitan perempuan ada tahap-tahap pelaksanaanya, seperti yang diungkapkan oleh ibu Era sebagai dukun bayi:

"Biasanya orang tua yang akan mengkhitan anak perempuan itu datang dulu ke rumah saya, untuk meminta tolong agar membantu mengkhitan anaknya sesuai adat Desa ini (Desa Rawakalong), setelah itu saya bilang apa saja peralatan yang harus disiapkan, diantaranya: 1 . kain putih 2. Koin 3. pisau lipat/pisau kecil

Masyarakat Desa Rawakalong melaksanakan khitan perempuan biasanya 40 hari terhitung dari bayi lahir dan setelah itu diadakan pengajian tasyakuran untuk keselamatan anak yang telah dikhitan atau biasa dikatakan kekerikan oleh masyarakat Desa Rawakalong tersebut, dan setelah khitan dilakasanakan, adat istiadat di Desa Rawakalong yaitu paraji yang melakukan khitan akan diberikan sesajen oleh orang tua anak yang dikhitan berupa makanan yaitu uli, pisang dan bahan pokok lainnya, Seperti yang diungkapkan oleh Ibu Era ${ }^{62}$.

Acara sunat perempuan dengan laki-laki sangatlah berbeda cara pelaksanaannya. Jika pada sunat anak laki-laki biasanya acaranya sangat meriah, sedangkan pada anak perempuan lebih sederhana. Di Desa Rawakalong biasanya jika

${ }^{61}$ Ustad Darwis S.Ag Tokoh Agama di Desa Rawakalong, Wawancara Pribadi, Rawakalong, 29 Maret 2019, jam 13.00 WIB s/d selesai, dan Ustadzah Hj Yohanah, Ketua Majlis

62 Talim al-Hidayah di Desa Rawakalong, Wawancara Pribadi, Rawakalong, 29 Maret 2019, jam15.00 WIB s/d selesai 
ada orang tua yang menyunatkan anak laki-lakinya, maka tetangga akan datang untuk nyumbang yaitu datang ke rumah yang mempunyai acara dengan membawa beras, mie, krupuk dan ada juga yang memberikan uang. Sedangkan jika pada sunat perempuan yaitu hanya mengundang beberapa tetangga dekat untuk selametan dan tradisi nyumbang dilakukan pada saat melahirkan saja. Acara selametan dilaksanakan setelah maghrib atau setelah isya, tergantung dari permintaan orang tua. Keluarga akan mengundang tetangga dengan menggunakan undangan atau menyuruh seseorang untuk datang ke setiap rumah tetangga yang di undang. adapun tsyakuran di sini disertai potong rambut bayi karena itu sudah adat istiadat di Desa Rawakalong.

\section{Tahap Pelaksanaan}

Menurut Ibu Era sebagai dukun bayi yang mengkhitan anak perempuan, pelaksanaan khitan bayi perempuan yaitu: "Khitan Perempuan itu beda dengan khitan laki-laki, biasanya khitan laki-laki itu dibawa ke dokter khitan, tetapi kalau khitan perempuan untuk masyarakat Desa di sini itu cukup dilaksanakan di rumah. Proses khitan perempuan yaitu hanya sebagai simbol, maksudnya khitan perempuan itu yang ditoreh bukan alat kelaminnya melainkan selaput putih pada klitoris tersebut, terlebih dahulu diberi sarapan/tatakan dengan kain putih yang sudah disiapkan lalu meletakan koin di bawah klitoris serta menorehnya dengan pisau kecil”.

Sebelum prosesi sunat perempuan dilaksanakan dukun bayi tersebut membaca doa atau jampe-jampe terlebih dahulu agar tidak mengeluarkan darah dalam proses mengkhitan. Doa yang dibacakan itu dalam bahasa sunda yang intinya meminta keselamatan anak tersebut. Jadi dapat disimpulkan jika proses pelaksanaan sunat perempuan dibagi menjadi dua tahap yaitu: tahap persiapan sunat perempuan dan tahap pelaksanaan sunat perempuan. Proses pelaksanaan sunat perempuan dilakukan oleh dukun bayi. Masyarakat memilih dukun karena didorong oleh faktor pendidikan masyarakat yang masih rendah sehingga masih menjalankan tradisi sunat seperti yang dilakukan nenek moyang mereka secara turun-temurun. 


\section{KESIMPULAN}

Berdasarkan uraian pada bab-bab sebelumnya, serta hasil penelitian yang telah dilakukan oleh penulis, maka dapat ditarik beberapa kesimpulan, diantaranya sebagai berikut:

1. Pendapat para ulama tentang khitan

\begin{tabular}{|c|c|c|}
\hline Madzhab & Laki-laki & Perempuan \\
\hline Hanifah & Sunnah & Baik/Sunnah \\
\hline Malik & Sunnah & Sunnah \\
\hline Syafi'i & Wajib & Wajib \\
\hline Hambali & Wajib & Wajib/Sunnah \\
\hline
\end{tabular}

2. Khitan perempuan yang dilaksanakan di Desa Rawakalong hanya sebagai simbol. Pelaksanaan khitan pada bayi perempuan di desa tersebut memiliki dua tahapan, yaitu: tahap persiapan yaitu bayi perempuan yang akan dikhitan diberi sarapan/tatakan dengan kain putih yang sudah disiapkan terlebih dahulu. Adapun tahap pelaksanaan dengan meletakan koin di bawah klitoris bersamaan dengan pembacaan doa atau jampe-jampe dengan Bahasa Sunda yang dibaca oleh paraji, lalu menorehnya dengan pisau kecil atau pisau lepit. Khitan perempuan tersebut merupakan sebuah tradisi yang sudah dilaksanakan sejak zaman dahulu (nenek-moyang mereka).

3. Khitan perempuan di masyarakat Desa Rawakalong biasa disebut dengan kekerikan, menurut pandangan tokoh agama dan masyarakat merupakan tradisi bagi masyarakat tersebut dan sesuai dengan hukum yang ada di dalam syariat Islam. Dan pelaksanaannya sebatas simbolis yaitu dengan ditorehkan sedikit, hal ini sesuai dengan anjuran Nabi kepada seorang wanita juru khitan anak perempuan yang biasa dipanggil Ummu ,atiyah yang artinya: “Lakukanlah khitan dan jangan berlebihan (potonglah sedikit dengan ringan), karena kalau hanyamemotong sedikit(tidak berlebihan), dapat menjadikan wajah lebih ceria dan disukai suami”. 


\section{DAFTAR PUSTAKA}

Al-Bukhori, Abu Abdillah Muhammad bin Ismail, al-Jami al-Shohih, Daarut Tuq anNajat, $1422 \mathrm{H}$

Hanbal, Abu Abdillah Ahmad bin Muhammad bin, Musnad al-Imam Ahmad bin Hanbal, Muassasatu al-Risalah, 2001

Al-Khurosani Abu Abdurahman Ahmad bin Syueib, al-Mujtaba Min al-Sunan, Maktabah al-Matbue ah al-Islamiah, 1986

An-Nisaburi, Abu al-Hasan Muslim bin al-Hajaj al-Qusyairi al-Jami al-Shohih, Darul Ihyait Turos Bairut, t.t

Al-Darimi, Abu al-Hatim Muhammad bin Hibban, al-Ihsan fi at-Taqribi as-Shohih, Muassasatu al-Risalah Bairut, t.t

Al-Tobroni, Abu al-Qasim Mu 'jam al-Kabir, Maktabah Ibnu al-Tamimiyah, Kairo, t.t Al-Syafie i, Abu al-Qasim Ali bin Hasan, Tarikh Madinatu al-Dimasko, Daaru al-Fiqr, 1995

Al-Baihaqi, Abu Bakar Ahmad bin Husein, Sunan al-Shogir li al-Baihaqi, Jamiah alDirosah al-Islamiah Pakistan, 1989

Al-Ruyani, Abu Bakar Muhammad bin Harun, Musnad al-Ruyani, Muasis al-Qurtubah Kairo, 1416 H

As-Sijistani, Abu Daud Sulaiman bin al-As'eab, Sunan Abu Daud, Maktabah al„Asriyah: Bairut, t.t

Al-Baghowi, Abu Muhammad al-Husein bin Maseeud, Syarh al-Sunnah, al-Maktabah al-Islamiah Dimaskus, Bairut, 1983

al-Nawawi, Abu Zakaria Muhyiddin Yahya Bin Syaraf, Minhajal-Thalibin Wa Umdatu al-Muftin, Beirut: Dar al-Fikr, 1425 H/2005 M 62

al-Hanbali, Abu Muhammad Abdullah bin Ahmad bin Qudamah, al-Mughni li ibni alQudamah, Kairo: Maktabah al-Qahiro 1388 H/1968 M

Asrori, Achmad Maecruf, Ber-Khitan Akikah Kurban Yang Benar Menurut Ajaran Islam, Surabaya:Al-Miftah, 1998

Al-,,Asqalani, Ahmad ibn „Alî ibn Hajar, Fathal-Bari Bi Syarhi Shohihil Bukhori, Saudi, 2001

Ramali, Ahmad, Peraturan-peraturan untuk Memelihara Kesehatan dalam Hukum Syara 'Islam, Jakarta:Balai Pustaka, 1956 
Fathullah, Ahmad lutfi, Fiqh Khitan Perempuan Jakarta:al-Mughni dan Mitra Inti, 2006

Aryani, Aini, Khitan Bagi Wanit, Haruskah?, (Rumah Fiqih Publishing, Setiabudi: Jakarta Selatan)

Munir, Akmal Abdul, Hukum Khitan Wanita Menurut Hukum Islam, Makalah, 2007

Ahsin W, Al Hafidz, Fikih Kesehatan, Jakarta, Amzah, 2010

Sutopo, Ariesto Hadi dan Arief, Ardianus, Terampil Mengolah Data Kualitatif Dengan NVIVO. Penerbit Prenada Media Group: Jakarta 2010

al-Hanafi, Fakhruddin Ustman Bin Ali al-Zilaei, Tabyin al-Haqaiq Syarh Kanzu alDaqaiq, (Kairo: al-Matba ${ }^{\text {ee }}$ ah al-Kubro al-Amiriah) Cet ke-1, $1313 \mathrm{H}$

Hathout, Hassan, Revolusi Lentera Perempuan, Obstetri dan dalam Tinjauan Islam, Jakarta: Remaja Rosdakarya, 1996

Yanggo, Huzaemah Tahido, Hukum Keluarga Dalam Islam, Jakarta:Yayasan Masyarakat Indonesia Baru, 2013

Al Jauziah, Ibnu Qayyim, Tuhfatul Maudud fii Ah kamil Maulud, Sudan: Maktabah Qayyimah, 1350 H 63 M.Echols, John, \& Hassan Shadili, Kamus Inggris Indonesia Jakarta: Gramedia, 1995

Moleong, Lexxy, Metode penelitian kualitatif, Bandung, remaja Rosdakarya, 1990

Margono, Metodologi Penelitian Pendidikan Jakarta: PT Rineka Cipta, 2006

Suryadilaga, Muhammad Alfatih, Aplikasi Penelitian Hadis Dari Teks ke Konteks, Yogyakarta:Teras, 2009

Hasan, M. Ali, Masail Fiqhiyah Al-Hadisah: Pada Masalah-Masalah Kontemporer Hukum Islam, Jakarta:Raja Grafindo Persada, 2003

Dinata, Nana Syaodih Sukama, Metode Penelitian Pendidikan, Bandung: Remaja Rosda karya, 2013

Muhajir, Noeng, Metode Penelitian Kualiitatif, Yogyakarta: Rake Sarasia, 1996

Utomo, Setiawan Budi, Fiqih Aktual: Jawaban Tuntas Masalah Kontemporer, Jakarta: Gema Insani Press, 2003

Al-Jabbar, Suhaib Abdul, al-Jami' al-Shohih li al-Sunan wa al-Asanid, t.t.p.

Arikunto, Suharsimi, Prosedur Penelitian: Suatu Pendekatan Praktek Jakarta: PT Rineka Cipta, 2002

Hadi, Sutrisno, Metodelogi Research, Yogyakarta: Ad Affset, 1989 
Haq, Syeikh Jadal Ali Jadal Haq tentang khitan, dalam buku Tim Riset Penerbit alQira $^{e c} a$, Khitan dalan prespektif syariah dan kesehatan, Dar al-Qira"ah, Kairo, Mesir, 2007

al-Qira "eah, Tim Riset Penerbit, Haqiqah al-Khitan Syar'iyyan wa Thibbiyyan, Dar alQira ${ }^{e e}$ ah, Kairo, Mesir, 2007

Sekaran, Uma, metode penelitian untuk bisnis, Jakarta: Salemba Empat, 2006 Narimawati, Umi, Metodologi Penelitian Kualitatif dan Kuantitatif, 200864 
hhttps://www.ncbi.nml.nih.gov/pubmedhealth/PMHT0027071/

Wawancara dengan bapak syaeful machfud SE selaku staff Desa Rawakalong Kecamatan Gunung Sindur Kabupaten Bogor Tanggal 15 Maret 2019 jam 09.00-selesai, di kantol desa.

Wawancara dengan ibu Erawati selaku dukun bayi desa Rawakalong Tanggal 29 Maret 2019, jam 09.00- selesai, di rumah klinik.

Wawancara dengan Ustad Darwis S.Ag salah satu tokoh agama yang ada di Desa Rawakalong, 29 Maret 2019, jam13.00 - selesai, di rumah.

Wawancara dengan Ustadzah $\mathrm{Hj}$ Yohanah selaku ketua Majlis Talim al-Hidayah di Desa Rawa kalong, Tanggal 29 Maret 2019, jam15.00- selesai, di klinik.

Profil Desa Rawakalong Tahun 2018, sumber data kependudukan desa Rawakalong.

Wawancara dengan ibu Amalia selaku sesepuh Desa Rawakalong Tanggal 29 Maret 2019, jam 16.30-selesai, di rumah ibu Amalia.

Wawancara dengan ibu Nila Pematasari, Orang Tua Dari Bayi Perempuan Yang Disuna di Desa Rawakalong, Rawakalong, 29 Maret2019, jam 15.00 - selesai, diklinik. 